\title{
Bibliotecas verdes e sustentáveis no Brasil
}

\author{
Sustainable and Green Libraries in Brazil
}

\author{
Nathalice Bezerra CARDOSO' \\ Elisa Campos MACHADO 1
}

\section{Resumo}

A pesquisa parte do pressuposto de que as bibliotecas públicas, municipais e estaduais no Brasil, em função de sua condição e de sua missão, devem ser as primeiras a adotarem princípios e práticas de sustentabilidade, com vistas a se constituírem como referências em equipamentos culturais verdes no país. Dessa forma, a presente pesquisa tem como objetivo refletir e discutir o conceito de informação ambiental e de biblioteca verde e sustentável, assim como identificar bibliotecas públicas certificadas no país, visando subsidiar a construção de políticas públicas nesta área. Apresenta os esforços do governo federal na gestão da informação ambiental e a ausência de estímulos para a adoção de práticas sustentáveis e certificação das bibliotecas que recebem investimentos públicos. Aponta passos para a certificação nas construções, design, arquitetura, gestão de recursos naturais e ambientais e educação ambiental em bibliotecas, bem como diretrizes para subsidiar a elaboração de políticas culturais e estimular os governos locais a adotarem princípios e práticas de sustentabilidade nas bibliotecas públicas brasileiras. Conclui que os investimentos governamentais na construção e modernização de bibliotecas públicas devem prever a adoção de princípios de sustentabilidade em seus prédios, serviços e práticas com o objetivo de incidir positivamente no desenvolvimento sustentável de sua região.

Palavras-chave: Bibliotecas públicas. Bibliotecas sustentáveis. Bibliotecas verdes. Biblioteconomia. Políticas públicas.

\begin{abstract}
The research assumes that public, state and municipal libraries in Brazil, due to its condition and its mission should be the first to adopt sustainability principles and practices in order to become a reference in green cultural equipment in the country. It aims to reflect and discuss the concept of environmental information and green and sustainable library, as well as identify certified public libraries in the country in order to support the construction of public policies in this area. It shows the efforts of the federal government in the management of environmental information, and the lack of incentives for the adoption of sustainable practices and certification of libraries that receive public investments. Points out steps for certification in construction, design, architecture, management of natural and environmental resources, and environmental education in libraries and guidelines to support the development of cultural policies and encourage local governments to adopt sustainability principles and practices in Brazilian public libraries. It concludes that government investments in construction and modernization of public libraries shall consider the adoption of sustainability principles in their buildings, services and practices with in order to have a positive impact on the sustainable development of their region.
\end{abstract}

Keywords: Public libraries. Sustainable libraries. Green libraries. Librarianship. Public policies.

\section{Introdução}

A problemática que envolve o meio ambiente na atualidade é caracterizada por fatores culturais, educacionais, sociais e econômicos que permeiam a sociedade. Além disso, a melhoria da qualidade de vida no planeta está associada diretamente com a implementação de políticas públicas voltadas para o desenvolvimento sustentável.

\footnotetext{
1 Universidade Federal do Estado do Rio de Janeiro, Escola de Biblioteconomia, Programa de Pós-Graduação em Biblioteconomia. Av. Pasteur, 458, Urca, 22290-255, Rio de Janeiro, RJ, Brasil. Correspondência para/Correspondence to: N.B. CARDOSO. E-mail: <nathalice@gmail.com>.

Recebido em17/2/2016, reapresentado em 28/6/2016 e aprovado para publicação em 25/10/2016.
} 
O Brasil é um dos líderes mundiais em recursos naturais e, dessa maneira, tem a grande tarefa de trabaIhar intensamente na construção de políticas públicas voltadas para a preservação do meio ambiente e para o desenvolvimento sustentável, de maneira a regular, estruturar e induzir ações e práticas sustentáveis. Vale lembrar que o país sediou dois importantes eventos mundiais sobre a temática: a Conferência das Nações Unidas sobre Meio Ambiente e Desenvolvimento (ECO92) e a Conferência das Nações Unidas sobre Desenvolvimento Sustentável (Rio+20), ambas na cidade do Rio de Janeiro.

A participação organizada dos bibliotecários e das bibliotecas nesses eventos foi pontual. Na Rio+20, que ocorreu em 2012, cabe destacar a exposição organizada pela Biblioteca Nacional no Espaço do Saber, reservado pelo Ministério da Cultura (MinC), em que os visitantes tiveram acesso a livros impressos e digitais, além de um acervo fotográfico relacionado ao tema meio ambiente. Sabe-se que a biblioteca é um espaço de acesso e produção de informação e conhecimento e o bibliotecário, um dos profissionais responsáveis pela disseminação da informação; assim, acredita-se que é determinante que essa temática seja incorporada pelos agentes atuantes no campo da Biblioteconomia e da Ciência da Informação no Brasil, além de se transformarem em protagonistas nesse cenário.

No âmbito internacional, o envolvimento dos bibliotecários com as questões ligadas ao meio ambiente resultou no surgimento de um novo conceito de biblioteca, o green library, que tem como foco as construções sustentáveis, design, arquitetura, gestão de recursos naturais e ambientais, bem como a educação ambiental em bibliotecas. Com isso, muitas bibliotecas públicas e universitárias da Europa e dos Estados Unidos da América vêm adotando esse conceito e se transformando em bibliotecas verdes e sustentáveis.

Nesse contexto, compreende-se que o Brasil tem por missão adotar o conceito de bibliotecas verdes de maneira a orientar os governos locais a transformarem suas bibliotecas públicas municipais e estaduais em espaços culturais públicos verdes, de acesso à informação ambiental e de referência no incentivo às práticas sustentáveis. No entanto, para que isso ocorra é necessária a criação de diretrizes para que essas bibliotecas públicas adotem princípios de sustentabilidade em seus prédios, serviços e práticas. Cabe esclarecer que, em relação à concepção de biblioteca pública, o Brasil segue as diretrizes aprovadas pelo Manifesto da International Federation of Library Associations/ United Nations Educational, Scientific and Cultural Organization (IFLA/UNESCO) para a Educação, a Ciência e a Cultura em 1994 sobre bibliotecas, assim como as recomendações da Declaração de Caracas [1982] (Declaración de Caracas sobre la biblioteca pública como factor de desarrollo e instrumento de cambio social en América Latina y el Caribe-1985,1999), a qual expressa o compromisso da biblioteca pública da América Latina e Caribe com a região, reforçando seu papel no estímulo à participação cidadã e na vida democrática.

Segundo dados de abril de 2015 do Sistema Nacional de Bibliotecas Públicas, órgão subordinado à Diretoria de Livro, Leitura, Literatura e Bibliotecas da Secretaria Executiva (SE) do Ministério da Cultura (MinC), o país conta com 6102 bibliotecas públicas municipais e estaduais distribuídas nos 26 estados e no Distrito Federal. É o equipamento público cultural mais presente nos municípios brasileiros, com potencial para se transformar em um centro de apropriação, produção e difusão de informação e conhecimento ambiental.

Dentro desse contexto, a presente pesquisa propôs uma reflexão acerca dos conceitos de informação ambiental e de bibliotecas verdes e sustentáveis, com vistas a intentar diretrizes nacionais para que as bibliotecas públicas mantidas pelo Estado sejam as primeiras a incorporarem os princípios da sustentabilidade e a se constituírem referências de equipamentos culturais verdes no país. Caracteriza-se como uma pesquisa aplicada, qualitativa, que utilizou como procedimentos técnicos a pesquisa bibliográfica e documental e o levantamento de informações por meio da observação assistemática e entrevista estruturada.

\section{Informação ambiental}

As discussões que vêm sendo travadas no nível internacional, a exemplo da Cúpula das Nações Unidas sobre o Desenvolvimento Sustentável que ocorreu 
em 2015, têm enfatizado a incompatibilidade entre desenvolvimento sustentável e os padrões de produção e consumo vigentes no mundo e a necessidade de repensar o modelo de desenvolvimento atual. Novos meios de exploração dos recursos naturais, novos critérios de investimentos e novos paradigmas técnico-científicos estão na pauta dessas conferências e a disseminação da informação ambiental é um princípio básico para enfrentar essas mudanças.

Nesse sentido, Vasconcelos (1998, p.24) traz uma boa contribuição quando esclarece que:

[...] O desenvolvimento sustentável tem na informação ambiental um elemento fundamental para sua viabilização, principalmente em função de alguns princípios [...] o princípio da eficácia no uso de recursos naturais (a informação é necessária para a estruturação de processos produtivos menos perdulários no consumo de energia e matérias-primas); o princípio da diversidade (a informação permite a identificação e a potencialização de mercados e recursos locais) e o princípio da descentralização (sendo a informação utilizada na capacitação dos atores sociais, que têm importantes papéis específicos na construção de uma sociedade sustentável social, econômica e ambientalmente).

A disseminação da informação ambiental é essencial, pois colabora para ampliar o conhecimento da sociedade a respeito do meio ambiente e para a adoção de práticas sustentáveis e consequente melhoraria da qualidade de vida de uma determinada população, ou seja,

[...] um tipo de informação científica e tecnológica que contribui para a preservação de ambientes naturais e dos ambientes construídos pelo homem, e é imprescindível para que a crise ambiental atual seja superada com sucesso. Porém, como não há conexão entre os mundos da informação e a realidade das populações atingidas pelas políticas públicas ambientais, faz-se necessário que os profissionais da informação procurem facilitar a difusão da informação ambiental, contribuindo para o desenvolvimento sustentável (AMORIM, 2004, p.1).

A preocupação com as mudanças climáticas, o consumo desenfreado e a escassez dos recursos naturais resulta em ampliação das demandas por informação ambiental pela sociedade, seja no nível local, regional, nacional ou internacional. Para Hazen (1997 p.31), "o acesso à informação tem que ser entendido como integrante da democracia ambiental, pois ela é vital para instrumentar a sociedade. Senão caímos numa democracia fictícia". Dessa forma, vale registrar que a constituição do Sistema Nacional de Informação do Meio Ambiental (SINIMA) e a garantia de prestação de informação sobre meio ambiente estão presentes na Política Nacional do Meio Ambiente (PNMA) no seu $9^{\circ}$ Artigo, que trata dos instrumentos para viabilizá-la (BRASIL, 1981), e na Lei no 10.650, de 16 de abril de 2003, que regulamenta o acesso à informação ambiental (BRASIL, 2003).

O Instituto Brasileiro do Meio Ambiente e dos Recursos Naturais Renováveis (IBAMA), por ser o órgão executor da PNMA, gerencia o Centro Nacional de Informação Ambiental (CNIA) que atua na disseminação da informação ambiental. O CNIA, além de ser o centro coordenador da Rede Nacional de Informação sobre o Meio Ambiente, oferece serviços que envolvem a produção e disseminação da informação ambiental, como biblioteca digital, banco de imagens, videoteca, produção, edição e venda de publicações, intercâmbio bibliográfico, acesso a legislação ambiental Federal, thesaurus de meio ambiente, entre outros.

Apesar dos avanços implementados pelo governo nos últimos tempos na organização e disseminação da informação ambiental, é importante lembrar que a produção de conhecimento acerca do tema é responsabilidade de diferentes tipos de instituições governamentais e não governamentais. Mais importante ainda é lembrar que a apropriação da informação pelo cidadão envolve vários fatores.

Dessa forma, vale lembrar Barreto (2002, p.72) quando argumenta que o conhecimento é o destino final da informação, assim, "conhecer é um ato de interpretação individual, uma apropriação do objeto informação, pela estrutura mental de cada sujeito". Além disso, é importante levar em consideração que "a simples percepção e sensibilização para o ambiente não expressa o aumento da consciência, o que faz com que se retorne o argumento sobre cidadania: a consciência para ser ecológica precisa ser crítica" (Loureiro, 1998, p.124). É nesse contexto que a educação ambiental se

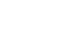


apresenta como uma ferramenta de apropriação da informação sobre meio ambiente e sustentabilidade, lançando mão de processos pedagógicos para o desenvolvimento da consciência crítica. Como explicita bem a Organização das Nações Unidas para Educação, Ciência e Cultura (1999, p.56):

Uma das metas básicas da educação ambiental é conseguir que as pessoas e as comunidades compreendam o caráter complexo do meio ambiente natural e artificial, resultante da inter-relação de seus aspectos biológicos, físicos, sociais, econômicos e culturais e adquirir o conhecimento, os valores, as atitudes e as aptidões práticas que permitam participar, de forma responsável e eficaz, no trabalho de prever e de resolver problemas ambientais e de uma gestão qualitativamente apropriada do meio ambiente.

No Brasil, foi no ano de 1999, por meio do $2^{\circ}$ Artigo da Lei federal n 9.795 (BRASIL, 1999), que a Educação Ambiental passou a ser um componente essencial e permanente da educação nacional, devendo estar presente, de forma articulada, em todos os níveis e modalidades do processo educativo, em caráter formal e não-formal. Assim como as escolas, as bibliotecas públicas municipais e estaduais, na sua função cultural e educativa não-formal, têm capacidade técnica para atuar com a educação, colaborando para a disseminação e apropriação da informação ambiental. De forma prática, o Ministério do Meio Ambiente deu início ao projeto Sala Verde no ano de 2000 com o objetivo de incentivar a implantação de espaços socioambientais os quais atuem como potenciais centros de informação e formação ambiental.

O projeto Sala Verde foi uma tentativa de ampliar os espaços de informação ambiental. No entanto, sua execução não levou em consideração uma potencial articulação com o MinC, que detém, por meio do Sistema Nacional de Bibliotecas Públicas, a articulação com as mais de 6 mil bibliotecas públicas municipais e estaduais, ou mesmo com o Ministério da Educação, o qual responde pelas bibliotecas escolares no país. Partiu de um modelo de atendimento por demanda com o compromisso da instituição beneficiada se dedicar a manter um espaço com caráter de biblioteca voltado para a educação ambiental. Atualmente, segundo - Ministério do Meio Ambiente, o país possui 363 Salas Verdes instaladas em diferentes espaços, como universidades, prefeituras, associações, bibliotecas públicas, comunitárias, entre outros.

\section{Bibliotecas verdes e sustentáveis}

Antonelli (2008) afirma que nos EUA o Movimento Biblioteca Verde surgiu no início de 1990, no entanto só ganhou popularidade na biblioteconomia por volta de 2003. Segundo o autor, o Movimento Biblioteca Verde:

[...] é composto de um número crescente de bi-bliotecários, bibliotecas, cidades, faculdades e campus universitários comprometidos com a transformação de bibliotecas, reduzindo o seu impacto ambiental no planeta. Esta inovação está acontecendo com a construção de prédios de bibliotecas e a adaptação de instalações de biblioteca existentes, oferecendo serviços de biblioteca verdes e, abraçando práticas ambientalmente favoráveis e sustentáveis dentro da biblioteca (ANTONELLI, 2008, p.1, tradução nossa) ${ }^{2}$.

Cabe esclarecer que os termos 'bibliotecas sustentáveis' e 'bibliotecas verdes' normalmente são utilizados como sinônimos no campo da arquitetura e construção da biblioteca (ALBERTS, 2012). No entanto, ser verde é apenas um passo para se tornar sustentável.

De acordo com Miller (2010), para uma biblioteca tornar-se verde são necessárias algumas ações que, adaptadas à realidade brasileira, podem ser divididas em quatro passos: plano de ação, projeto arquitetônico, serviços e educação ambiental. O autor ressalta que a responsabilidade por essa transformação é de todos, portanto, o envolvimento da equipe da biblioteca é determinante para o sucesso do projeto. Nesse sentido, sugere a criação de um Comitê Verde responsável por definir as ações, as inciativas, os programas e os projetos da biblioteca verde.

\footnotetext{
2 "It is comprised of a growing number of librarians, libraries, cities, towns, college and university campuses committed to greening libraries by reducing their environmental impact on the planet. This innovation is happening by building green library buildings, by greening existing library facilities, providing green library services, and embracing environmentally supportive and sustainable practices within the library".
} 
Especificamente no que se refere ao projeto arquitetônico e à construção do prédio, Miller (2010) ressalta a necessidade de levar em consideração os fatores ambientais locais para que a biblioteca se torne sustentável ao ponto de obter a certificação. Existem alguns tipos de certificações que merecem destaque: o inglês Building Research Establishment Environmental Assessment, o norte-americano Leadership in Energy and Environmental Design (LEED) e o francês Haute Qualité Environmentale (HQE).

Várias bibliotecas norte-americanas vêm adotando a metodologia de certificação LEED, como por exemplo: a Darien Public Library, em Connecticut; a Bronx Public Library, em New York; a Hillside Public Library, no Oregon; e Chicago Public Library, Concordia University Library e Santa Monica Public Library.

No Brasil, de acordo com Pereira e Salgado (2013), os certificados mais utilizados são o LEED, emitido pela Green Building Council Brasil, e o certificado Alta Qualidade Ambiental (AQUA), emitido pela Fundação Vanzoline. Este último trata-se de uma adaptação brasileira do Haute Qualité Environnementale. Sobre o LEED, este

[...] tem a função de identificar e informar a eficiência e o desempenho ambiental do edifício e oferece diferentes escopos de certificação, para novas construções, para edifícios já existentes, para interiores, para áreas externas, entre outros. O sistema de avaliação é baseado em créditos que são ponderados para gerar uma classificação de desempenho ambiental do empreendimento em níveis (GREEN BUILDING COUNCIL BRASIL, 2014, p.1).

Já para obter a certificação AQUA, é necessário implantar um sistema de gestão do empreendimento e atender diferentes categorias de qualidade ambiental do mesmo, as quais envolvem tanto o edifício quanto o entorno, a escolha de produtos e sistemas, o canteiro de obras, a gestão de energia, água, resíduos, manutenção, conforto visual, olfativo, entre outros. A Fundação Vanzolini faz três auditorias presenciais ao longo do processo a fim de verificar se todos os critérios de sustentabilidade foram atendidos.

Cabe esclarecer que a obtenção do certificado LEED não é gratuita, sendo necessário o pagamento das taxas de registro do projeto junto ao Green
Building Council dos EUA; os valores diferem de acordo com a obra. Já para o certificado AQUA, é necessário o pagamento nas três fases: pré-projeto, projeto e execução, incluindo análise do projeto, auditorias, avaliação e uso da marca.

Além das certificações, a norma ISO/TR 11219: 2012 especifica os dados para o planejamento de edifícios de uma biblioteca. Ela é aplicável a todos os tipos de bibliotecas, em todos os países, principalmente, para as bibliotecas acadêmicas e públicas, sendo que o item 8 trata da sustentabilidade do edifício.

Pequenos detalhes são muito importantes para garantir um projeto de biblioteca verde, como a escolha da tinta, a qual deve ser, preferencialmente, à base de látex ao invés de óleo. Em relação à cor das paredes, Miller (2010) enfatiza que a escolha de uma tinta clara é importante, pois reflete o calor do sol e faz o espaço ficar mais claro durante o dia, reduzindo a necessidade de luz artificial.

No âmbito internacional, existem várias instituições as quais oferecem fontes de referência com informações sobre produtos e fabricantes, como a American Coating Association ou a Green Seal. No Brasil, existe a Ficha de Informações de Segurança de Produtos Químicos, que fornece informações sobre produtos químicos (substâncias ou misturas) relativas à segurança, à saúde e ao meio ambiente.

No caso da construção de uma nova biblioteca ou da reforma de uma existente, fica mais fácil implantar em seu projeto critérios de sustentabilidade visando à certificação. Entretanto, além da construção de edifícios sustentáveis, existem várias práticas que podem ser aplicadas no dia a dia de uma biblioteca para diminuir o impacto do homem sobre a natureza e promover o desenvolvimento sustentável da região. Nesse sentido, Miller (2010) ressalta que para uma biblioteca se tornar verde os serviços prestados também devem ser levados em consideração.

No que tange aos serviços, é possível evitar o desperdício de material, como papel para impressão de documentos, por exemplo. É possível incentivar a utilização de publicações digitais, audio-books, periódicos eletrônicos, Disco Compacto (CD) e Disco Versátil Digital (DVD), evitando, assim, a impressão 
de cópias. Outra questão importante abordada por Miller (2010) é o descarte de publicações do acervo da biblioteca, as quais deveriam ser reutilizadas ou recicladas. Ao tratar dos serviços de biblioteca, Miller (2010) inclui a aplicação da gestão ambiental no ambiente de trabalho, pois, além de despertar a curiosidade de quem frequenta a biblioteca, servirá como exemplo de comportamentos ecologicamente corretos.

No Brasil, a Agenda Ambiental de Administração Pública, publicada pelo Ministério do Meio Ambiente, tem como objetivo geral implementar a gestão ambiental nas atividades administrativas e operacionais do Governo (BRASIL, 2011). A agenda apresenta princípios de mudanças comportamentais que vão desde mudança nos investimentos, compras e contratação de serviços até orientações sobre a gestão adequada dos resíduos sólidos gerados no trabalho e dos recursos naturais utilizados.

Em junho de 2014 foi lançado o "Manual de Compras Sustentáveis" (CONSELHO EMPRESARIAL BRASILEIRO PARA O DESENVOLVIMENTO SUSTENTÁVEL, 2014), que oferece ao profissional da área de compras, da iniciativa privada, uma ferramenta prática e complementar para tomada de decisão, a qual incorpora critérios de sustentabilidade na seleção de fornecedores e responde à necessidade das diferentes áreas envolvidas de buscar um consenso para a decisão da seleção de fornecedor. Apesar de ter sido criado para atender as empresas privadas, assim como a norma ISO 14001, também pode servir como ferramenta de uso do poder público.

Evitar desperdício de material é essencial para reduzir a produção de lixo e diminuir o impacto que esses resíduos sólidos causam no meio ambiente. Pequenas mudanças de hábito de consumo e de comportamento são realmente relevantes para a conservação do meio ambiente e para obter um desenvolvimento sustentável. Dessa forma, cabe lembrar a regra dos cinco ' $R$ ', antes de jogar algo fora: reduza, reuse, recicle, respeite e responsabilize. A reciclagem pode ajudar até mesmo na arrecadação de dinheiro para compra de livros, ou na manutenção da biblioteca. Na hora de comprar equipamentos novos para a instituição, é importante optar por soluções ecológicas, que consomem menos energia ou recursos; um exemplo são os bebedouros: pode-se dar preferência para aqueles que não precisam de copos. A opção por lâmpadas de Light Emitting Diode (LED) também é recomendada, pois duram mais e gastam menos energia que as fluorescentes frias.

Outras pequenas mudanças de hábito, como apagar a luz e desligar o ar condicionado no final do expediente ou, ainda, não deixar portas e janelas abertas quando o ar estiver ligado, com certeza colaboram para economizar energia. Nesse mesmo sentido, é possível utilizar escadas ao invés de elevadores, o que, além de respeitar o meio ambiente, também é uma forma exercitar-se.

Qualquer resíduo ou equipamento eletrônico, como impressoras, scanners, telefones e celulares, também devem ser descartados em um lugar apropriado. Caso o equipamento não esteja em condição de ser doado, é possível cobrar do fabricante o descarte correto, pois, de acordo com a Lei n 12.305 de Resíduos Sólidos, a empresa também é responsável pelo destino correto dos materiais que produzem (BRASIL, 2010a).

O bibliotecário, por sua vez, deve contribuir de forma ativa para o desenvolvimento sustentável da região que atua, disseminando a informação ambiental e colocando em prática suas habilidades e competências como gestor de informação e educador ambiental. Ainda segundo Miller (2010), para a biblioteca se tornar sustentável há de se pensá-la como espaço para educação ambiental, contemplando programas e projetos voltados para a conscientização da comunidade e de seus usuários. As atividades de mediação de leitura podem dar bons resultados no que diz respeito ao despertar da consciência ambiental junto aos usuários, assim como a promoção de eventos sobre a temática ambiental - palestras, debates, oficinas, trabalhos de campo, exposições, concursos etc. Levar em consideração as datas comemorativas do Meio Ambiente para realização de atividades lúdicas também é de suma importância, principalmente, para promover o interesse das crianças.

Somando-se a isso, a Internet conta hoje com inúmeras ferramentas que podem ser extremamente úteis no desenvolvimento de atividades culturais voltadas para a temática da sustentabilidade. Uma dessas ferramentas é o blog Greening Your Library [https:// 
greeningyourlibrary.wordpress.com/]; nele são publicadas experiências, ideias, práticas, ferramentas, técnicas e eventos para ajudar as bibliotecas verdes, os bibliotecários e, consequentemente, a comunidade nesse sentido, além de divulgar uma lista de filmes voltados para a questão ambiental. Outro site importante é o Green Libraries [http://www.greenlibraries.org/], excelente fonte de informação para conhecer outras ações praticadas por bibliotecas verdes e sustentáveis pelo mundo. É importante, também, que a biblioteca mantenha seu acervo atualizado com obras sobre questões ambientais as quais envolvam o país, visando capacitar a equipe e auxiliar nas atividades de educação ambiental e culturais, desenvolvendo ações de difusão da informação ambiental na comunidade.

\section{Diretrizes para bibliotecas públicas verdes no brasil}

Com base na análise dos Relatórios de gestão da diretoria de livro, leitura e literatura dos anos de 2008 a 2010 (BRASIL, 2010b) e dos processos administrativos de implantação e modernização das chamadas 'Bibliotecas Referência', apoiadas pelo Programa Mais Cultura do MinC, foi possível constatar, no período acima referido, que o governo federal não adotou diretrizes específicas para garantir a implementação do conceito de biblioteca verde e sustentável nas bibliotecas públicas que receberam recursos financeiros para implantação ou modernização. Independentemente disso, das quatro bibliotecas referência apoiadas pelo governo federal à época, foi possível constatar que apenas uma delas adotou o conceito e recebeu o certificado LEED; trata-se da Biblioteca Parque do Rio de Janeiro, localizada na região central da cidade do Rio de Janeiro.

Assim, a partir das reflexões acerca do conceito de bibliotecas verdes e da análise da experiência da $B E P R J$, entende-se que para uma biblioteca pública se transformar em biblioteca verde é preciso:

- Estabelecer um Comitê Verde envolvendo funcionários da biblioteca e comunidade;

- Elaborar um plano de ação com os objetivos, metas, metodologia para implantação das ações e mudanças previstas ao longo de um determinado tempo. Esse plano deve levar em conta os recursos necessários;
- Conscientizar a comunidade local a respeito dos benefícios que a biblioteca verde pode trazer;

- Implantar no projeto arquitetônico de construção do edifício de uma nova biblioteca baseado nos critérios de sustentabilidade, de acordo com a ISO/TR 11219:2012, visando, se possível, a certificação ambiental LEED, ou AQUA;

- Trabalhar hábitos e atitudes, procedimentos, projetos e ações nas bibliotecas existentes que não possuem recursos ou condições para reformas;

- Aplicaragestãoambiental no ambiente de trabalho preocupando-se com as aquisições ecológicas, quer sejam materiais de escritório, móveis, equipamentos ou produtos e ferramentas de limpeza;

- Adotar a Agenda Ambiental de Administração Pública (A3P) levando-se em consideração o Manual de Compras Sustentáveis e a norma ISO 14001 para tomada de decisão na seleção de fornecedores;

- Economizar recursos naturais, utilizar bem os recursos financeiros e preocupar-se com os demais materiais utilizados nos serviços da biblioteca para reduzir a produção de lixo, mitigando o impacto que esses resíduos sólidos causam no meio ambiente;

- Adotar a educação ambiental como princípio no processo de formação dos funcionários e usuários da biblioteca;

- Manter uma coleção atualizada sobre as questões ambientais a fim de desenvolver ações de difusão da informação ambiental na comunidade;

- Contribuir com a disseminação e o acesso da informação ambiental visando a qualidade de vida da população;

- Incentivar pesquisas na área;

- Criar programas e projetos pautados na Educação Ambiental que, além de incentivarem a leitura, visem à conscientização dos usuários sobre ações ecologicamente corretas;

- Levar em consideração as datas comemorativas do meio ambiente para realização de palestras, debates, oficinas, trabalhos de campo, exposições, concursos, entre outras ações culturais;

- Incentivar a utilização de publicações digitais, audiobooks, periódicos eletrônicos, CD e DVD, evitando a impressão; 
- Descartar publicações do acervo da biblioteca preocupando-se com a reutilização das mesmas, doando-as ou reciclando-as;

- Colocar em prática a regra dos cinco 'R': reduza, reuse, recicle, respeite e responsabilize.

Cabe ressaltar que essas recomendações são, em sua maioria, consideradas ações possíveis de serem realizadas em qualquer biblioteca, bastando o comprometimento dos gestores, bibliotecários e demais funcionários com a sustentabilidade e o meio ambiente. Já no nível federal, é imprescindível que o Sistema Nacional de Biblioteca Públicas se articule com o CNIA para facilitar o acesso às bases de dados, às publicações e informações ambientais para as bibliotecas públicas, assim como com outros órgãos governamentais e não governamentais que estão liderando o processo de construção e disseminação de informação ambiental. Além disso, disponibilizar exemplos de sucesso de práticas e projetos de bibliotecas verdes também é uma forma de estimular a propagação dessa ideia no país.

\section{Conclusão}

Tendo em vista que a questão ambiental é uma prioridade no mundo atual, é imperativo que os governos e a sociedade se mobilizem na busca de soluções sustentáveis. Dessa forma, o campo da Biblioteconomia e da Ciência da Informação não podem ficar à parte dessa questão. Os investimentos governamentais para a construção e modernização de bibliotecas públicas devem levar em consideração critérios e diretrizes os quais orientem o funcionamento de bibliotecas verdes no país com capacidade de incidir positivamente no desenvolvimento sustentável de sua região.

Com base na experiência executada na BPERJ e nos estudos e reflexões realizados durante esta pesquisa, foi possível elencar diretrizes para auxiliar a elaboração de políticas públicas que visem melhorar a relação das bibliotecas públicas brasileiras com o meio ambiente, no sentido de transformá-las em bibliotecas verdes. No que tange à construção desse tipo de instituição no Brasil, a BPERJ é considerada uma referência para a área e certamente estimulará outros gestores públicos a implementar o conceito em suas localidades.

Como resultado, esta pesquisa gerou um documento intitulado 'Diretrizes para Bibliotecas Públicas Verdes no Brasil', encaminhado ao Sistema Nacional de Bibliotecas Públicas do MinC como forma de contribuição para a construção de normativas brasileiras na área. Espera-se que os resultados desta pesquisa ampliem a reflexão e a adoção do conceito bibliotecas verdes e sustentáveis no país.

\section{Colaboração}

Todos os autores contribuíram na concepção e desenho do estudo, análise de dados e redação final.

\section{Referências}

ALBERTS, S. J. Sustainable library design: A case study of library construction on the East end of Long Island, N.Y from 2007 to 2009. In: ANTONELLI, M.; MCCULLOUGH, M. Greening libraries. Los Angeles: Library Juice Press, 2012.

AMORIM, R. R. A responsabilidade social dos profissionais da informação e a preservação do meio ambiente. In: CONGRESO INTERNACIONAL DE INFORMACIÓN, 2004. Cuba. Anais... Havana: IDICT, 2004.

ANTONELLI, M. The green library movement: An overview of green library literature and actions from 1979 to the future of green libraries. Eletronic Green Journal, v. 27, 2008. Available: <http://escholarship.org/uc/item/39d3v236?query=The\%20 Green\%20Library\%20Movement:\%20An\%20Overview\%20 of $\% 20$ Green $\% 20$ Library $\% 20$ Literature $\% 20$ and $\% 20$
Actions\%20from\%201979\%20to\%20the\%20Future\%20 of\%20Green\%20Libraries\#page-5>. Cited: Jan. 10, 2016.

BARRETO, A. A. A condição da informação. São Paulo em Perspectiva, v. 16, n. 3, p. 67-74, 2002.

BRASIL. Lei n 6.938, de 31 de agosto de 1981. Dispõe sobre a Política Nacional do Meio Ambiente, seus fins e mecanismos de formulação e aplicação, e dá outras providências. Diário Oficial da União. Brasília, 1 set. 1981. Disponível em: <http:// www.planalto.gov.br/Ccivil_03/Leis/L6938.htm>. Acesso em: 15 ago. 2015.

BRASIL. Lei n 9.795, de 27 de abril de 1999. Dispõe sobre a educação ambiental, institui a Política Nacional de Educação Ambiental e dá outras providências. Diário Oficial da União. 
Brasília, DF, 28 set. 1999. Disponível em: <http://www.planalto. gov.br/ccivil_03/leis/l9795.htm>. Acesso em: 15 ago. 2015.

BRASIL. Lei $n^{\circ} 10.650$, de 16 de abril de 2003. Dispõe sobre o acesso público aos dados e informações existentes nos órgãos e entidades integrantes do Sisnama. Diário Oficial da União. Brasília, 17 abr. 2003. Disponível em: <http://www. planalto.gov.br/ccivil_03/Leis/2003/L10.650.htm>. Acesso em: 15 ago. 2015.

BRASIL. Lei $n^{\circ} 12.305$, de 2 e agosto de 2010. Institui a Política Nacional de Resíduos Sólidos. Altera a Lei n 9.605, de 12 de fevereiro de 1998, e dá outras providências. Diário Oficial da União. Brasília, 3 ago. 2010a. Disponível em: <http://www. planalto.gov.br/ccivil_03/_ato2007-2010/2010/lei/l12305. htm> Acesso em: 15 ago. 2015.

BRASIL. MINISTÉRIO DA CULTURA. Relatório de gestão da diretoria de livro, leitura, literatura e bibliotecas. Rio de Janeiro: DLLLB, 2010b.

BRASIL. MINISTÉRIO DO MEIO AMBIENTE. A3P: agenda ambiental na administração pública. Brasília: Ministério do Meio Ambiente, 2011. Disponível em: <http://www.mma. gov.br/responsabilidade-socioambiental/a3p> Acesso em: 30 jun. 2014.

CONSELHO EMPRESARIAL BRASILEIRO PARA O DESENVOLVIMENTO SUSTENTÁVEL. Manual de Compras Sustentáveis. Rio de Janeiro: CEBDS, 2014. Disponível em: <http://cebds. org/wp-content/uploads/2015/09/Manual-de-ComprasSustent\%C3\%A1veis.pdf>. Acesso em: 13 jun. 2016.

DECLARACIÓN de Caracas sobre la biblioteca pública como factor de desarrollo e instrumento de cambio social en América Latina y el Caribe - 1985. Revista El libro en América Latina y el Caribe, n. 87, p. 55-60, 1999.
GREEN BUILDING COUNCIL BRASIL. GBC Brasil. Certificação LEED. São Paulo: GBC Brasil, 2014. Disponível em: <http:// www.gbcbrasil.org.br/sobre-certificado.php>. Acesso em: 10 jun. 2015.

HAZEN, S. Democracia ambiental. Nuestro Planeta. v. 8, n. 6, p. 31, 1997.

ISO/TR 11219:2012 - Information and documentation Qualitative conditions and basic statistics for library buildings - Space, function and design. Geneva: ISO, 2012. Available: <http://www.iso.org/iso/catalogue_detail.htm?csnumber $=50251>$. Cited: June 10, 2015 .

LOUREIRO, C. F. B. Reflexões sobre os conceitos de ecocidadania e consciência ecológica. In: MATA, S. F. (Org.). Educação ambiental desafio do século: um apelo ético. Rio de Janeiro: Terceiro Milênio, 1998.

MILLER, K. Public Libraries Going Green. Chigaco: ALA Editions, 2010.

ORGANIZAÇÃO DAS NAÇÕES UNIDAS PARA A EDUCAÇÃO, A CIÊNCIA E A CULTURA. Educação para um futuro sustentável: uma visão transdisciplinar para ações compartilhadas. Brasília: Editora Ibama, 1999.

PEREIRA, A. A.; SALGADO, M. S. Gestão de Projetos Habitacionais Sustentáveis no mercado imobiliário: estudo sobre o processo AQUA. In: SIMPÓSIO BRASILEIRO DE QUALIDADE DO PROJETO NO AMBIENTE CONSTRUÍDO, ENCONTRO BRASILEIRO DE TECNOLOGIA DE INFORMAÇÃO, 3., COMUNICAÇÃO NA CONSTRUÇÃO, 6., 2013, Porto Alegre. Anais.... Porto Alegre: ANTAC, 2013. p. 1-7.

VASCONCELOS, C. R. O papel das ONGs brasileiras na produção e disseminação de informação ambiental. 1998. Dissertação (Mestrado em Ciência da Informação) - Universidade Federal do Rio de Janeiro, Rio de Janeiro, 1998. 
